\title{
An efficient HILIC-MS/MS method for the trace level determination of three potential genotoxic impurities in aripiprazole active drug substance
}

\author{
Sumanth Mullangi ${ }^{1}$, Kunta Ravindhranath ${ }^{1 *}$ and Ravi Kiran Panchakarla ${ }^{2}$
}

\begin{abstract}
A sensitive and selective hydrophilic interaction liquid chromatography-tandem mass spectrometry (HILIC-MS/MS) method was developed and validated for trace analysis of potential genotoxic impurities (PGIs): 2,3-dichloroaniline (PGI-1), bis(2-chloroethyl) amine (PGI-2), and 2-chloroethylamine (PGI-3), in aripiprazole (APZ) active drug substance. Separation of analytes was achieved on ACE HILIC-N Column (HILN-5-1046U, $100 \times 4.6 \mathrm{~mm}, 5 \mu \mathrm{m}$ ) in gradient elution mode with mobile phase A [acetonitrile:ammonium formate buffer $(95: 5 \mathrm{v} / \mathrm{v})$ ] and mobile phase B [acetonitrile: ammonium formate buffer $(50: 50 \mathrm{v} / \mathrm{v})]$ at a flow rate of $0.8 \mathrm{~mL} / \mathrm{min}$. Developed method was linear in the concentration range of 8-100 ppm for PGI-1, 11-100 ppm for PGI-2, and 12.5-100ppm for PGI-3 with $R^{2}>0.996$. The developed method was accurate for quantification of each PGI with percent recoveries greater than 96\% and RSD (\%) not more than $5 \%$. The developed method was precise for quantification of PGIs in aripiprazole with RSD (\%) of not more than $4 \%$ for any of the PGIs. There was no interference of diluent peaks at the retention time of the PGIs and APZ in the method. All the PGIs and sample solutions were found to be stable at ambient laboratory temperature $\left(25 \pm 5^{\circ} \mathrm{C}\right)$ and refrigerated condition $\left(2-8^{\circ} \mathrm{C}\right)$ for a period of $48 \mathrm{~h}$. The developed HILIC-MS/MS method can be used for trace quantification of PGls in aripiprazole drug in quality control laboratories of the pharmaceutical industry.
\end{abstract}

Keywords: Aripiprazole, Genotoxic impurities, HILIC-MS/MS, Multiple reaction monitoring

\section{Introduction}

The assessment and control of impurities in pharmaceutical products, especially genotoxic/mutagenic impurities have received considerable attention in the recent years. International Council on Harmonization (ICH) provides guidance on assessment of genotoxic impurities in pharmaceuticals (International Council for Harmonization, n.d.-a; United states food and drug administration, n.d.). Active pharmaceutical ingredients typically contain a range of residual trace-level impurities arising from the reagents, starting materials, process intermediates and by-products generated

\footnotetext{
* Correspondence: ravindhranath.kunta@gmail.com

'Department of Chemistry, Koneru Lakshmaiah Education Foundation, Green Fields, Vaddeswaram-522 502, Guntur Dt., A.P, India

Full list of author information is available at the end of the article
}

during the course of synthesis (International Council for Harmonization, n.d.-b). The ICH M7 (International Council for Harmonization, n.d.-a) guideline proposed a threshold of toxicological concern value: $1.5 \mu \mathrm{g} /$ day. The limit for the determination of these impurities was set based on the maximum daily dose (MDD) of the active pharmaceutical ingredient (API).

Aripiprazole (APZ), 7-\{4-[4-(2,3-dichlorophenyl) piperazin1-yl] butoxy\}-3,4-dihydroquinolin-2(1H)-one (Fig. 1), is a D2/5-HT 1A/5-HT 2C partial agonist and a D3/4/5-HT 2A/ 5-HT 7 antagonist, with moderate serotonin transporter inhibitory, antihistaminic $\mathrm{H} 1$, and adrenolytic activities (Sharif et al., 2009). It is a member of a class of typical antipsychotic agents and is indicated in the treatment of positive and negative symptoms of schizophrenia and 


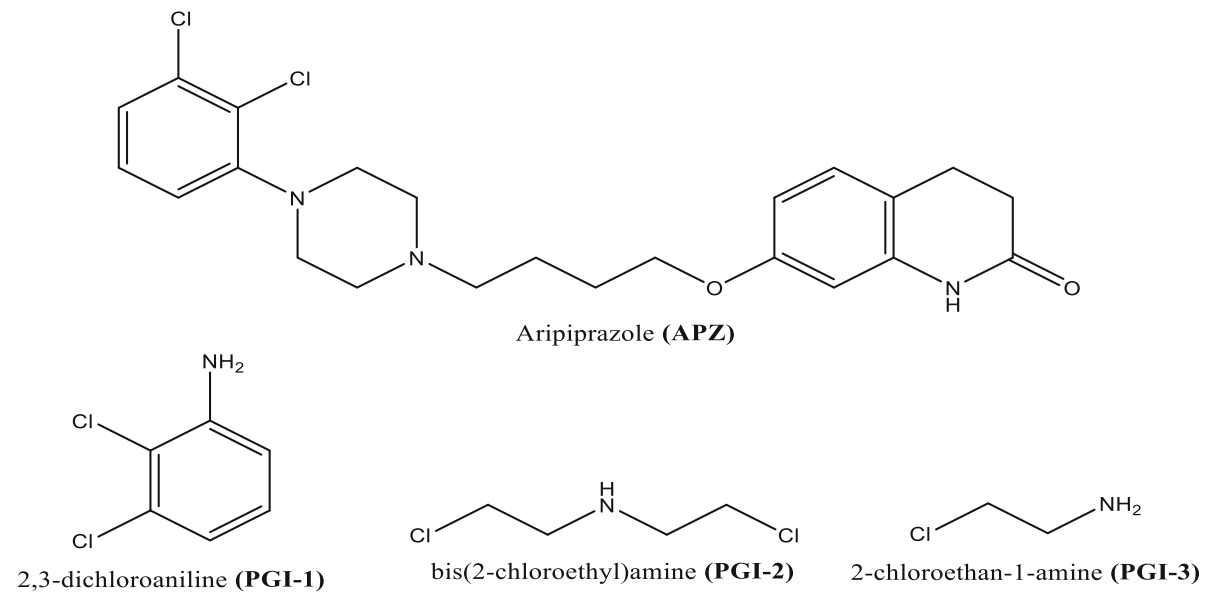

Fig. 1 Structures of aripiprazole and its potential genotoxic impurities (PGIs)

related disorders (Kwon et al., 2009). APZ has been approved by the Food and Drug Administration (FDA) for the treatment of acute manic and mixed episodes, in both paediatric patients and in adults. Several double-blind, placebo-controlled trials have proved the efficacy and safety of APZ for the said treatments (Keck et al., 2003; Sachs et al., 2006; Vieta et al., 2008; Keck et al., 2009).

Aripiprazole synthesis involves the utilization of 2, 3dichloro aniline (PGI-1), bis (2-chloroethyl) amine (PGI-2) and 2-chloro ethylamine (PGI-3). Therefore, it is quite possible that these intermediates used in the synthesis of the API can be present as impurities in the final product. Based on the structural alerts (Muller et al., 2006; Snodin, 2010), all the three impurities could be genotoxic in nature (potential genotoxic impurities, PGIs) and should be controlled at low levels according the regulatory guidelines (Robinson, 2010; McGovern \& Jacobson-Kram, 2006). Structures of these three PGIs and aripiprazole are presented in Fig. 1. Based on the maximum daily dose (MDD) of aripiprazole (30 mg/day), limit of three PGIs should be controlled below $50 \mathrm{ppm}$.

Methodologies have been developed for the determination of APZ via LC-MS/MS method in rat plasma (Liang et al., 2012) and in human plasma (Lin et al., 2009; Patel et al., 2013). There are also reports available for the simultaneous determination of APZ and its major metabolites by LC-MS/MS in human serum and plasma (Song et al., 2009; Caloro et al., 2012; Ambavaram et al., 2013; Kubo et al., 2005; Djordjevic Filijovic et al., 2014). But there are no published reports on the quantification of the potential genotoxic impurities in APZ using LC-MS/MS. Hence, the present investigation is devoted to develop and validate a simple, sensitive, accurate, and precise LC-MS/MS method for the trace level quantification of PGI-1, PGI-2, and PGI-3 in APZ.

\section{Materials and methods Safety concerns}

All the three impurities, PGI-1, PGI-2, and PGI-3, are considered to be potentially genotoxic. Therefore, all samples were handled under fume hood. During liquid chromatographic separation runs, column flow was collected separately in hazardous waste containers and disposed using appropriate institutional safety procedures.

\section{Materials and chemicals}

Aripiprazole (Purity > 99\%), procured from Chemxzen Labs Ltd., Hyderabad. 2,3-dichloroaniline (PGI-1; Purity $>99 \%$ ), bis (2-chloroethyl) amine (PGI-2; Purity > 98\%), 2-chloro ethylamine (PGI-3; Purity > 99\%) were purchased from Sigma-Aldrich, Bangalore. LC-MS grade acetonitrile, formic acid, and ammonium formate buffer were procured from Merck, Mumbai, India. Ultra-pure deionized water was obtained using Milli- $Q$ water purification system (Merck/Milli-Q ${ }^{\circ}$ Integral 3 System, USA).

\section{Instrumentation}

The liquid chromatography mass spectrometric (LCMS) system consisted of Shimadzu (Nexera X2) chromatographic separation unit (Shimadzu Corp, Kyoto, Japan) coupled with Shimadzu 8040 triple quadrupole mass analyzer (Shimadzu Corp, Kyoto, Japan). Data acquisition and integration were carried out using LC-MS Lab Solutions software (Shimadzu Corp, Kyoto, Japan). Calibrated automated micropipettes were used for preparation of all the samples during the analyses. Aqueous phase component in mobile phase was filtered through a $0.22-\mu \mathrm{m}$ polyvinylidene difluoride (PVDF) filtration membrane while the sample solutions were filtered through $0.22 \mu \mathrm{m}$ PVDF syringe filters (Millipore MA, USA) before the analysis. 


\section{Liquid chromatographic and mass spectrometric conditions \\ LC method conditions}

Chromatographic separation was achieved on ACE HILI C-N Column (HILN-5-1046U, 100× $4.6 \mathrm{~mm}, 5 \mu \mathrm{m}$ ) in HILIC mode. Mobile phase was composed of acetonitrile: ammonium formate buffer $(\mathrm{pH} \mathrm{6)}(95: 5 \mathrm{v} / \mathrm{v})$ (solvent A) and acetonitrile:ammonium formate buffer ( $\mathrm{pH}$ 6) (50:50 $\mathrm{v} / \mathrm{v}$ ) (solvent B). Gradient program was employed to achieve the separation between the analytes and APZ. Samples were analysed under gradient conditions at a flow rate of $0.8 \mathrm{~mL} / \mathrm{min}$ with total run time of $10 \mathrm{~min}$. Injection volume was $10 \mu \mathrm{L}$ in the method. Temperature for auto sampler was set at $25 \pm 5{ }^{\circ} \mathrm{C}$ and column oven was set at $35{ }^{\circ} \mathrm{C}$. Complete details of the LC method conditions are presented in Table 1.

\section{MS method conditions}

For the current method, mass spectrometer was operated with electrospray ionization (ESI) interface in positive mode. Mass spectrometer conditions for the developed method were capillary voltage, $3.0 \mathrm{kV}$; cone voltage, $15 \mathrm{~V}$; probe temperature, $150{ }^{\circ} \mathrm{C}$; nebulization and drying gas, nitrogen; drying gas flowrate, $900 \mathrm{~L} / \mathrm{h}$; CID gas, argon. Multiple reaction monitoring mode was employed for the qualification and quantitation of the three PGIs. For the qualification of the analytes, parent ion > daughter ion transitions selected in MRM mode were $163.1>126.3$ for PGI-1; $143.1>63.1$ for PGI-2, and $80.5>63.1$ for PGI-3 and for the quantitation of the analytes: $163.1>90.2$ for PGI-1; $143.1>107.1$ for PGI-2, and $80.5>45.1$ for PGI-3.

\section{Preparation of stock solutions and sample solutions}

The mass concentrations of PGI-1, PGI-2, and PGI-3 in acetonitrile amounted to $0.1 \mathrm{mg} / \mathrm{mL}$. All the individual primary stock solutions were stored under refrigerated condition $\left(2\right.$ to $\left.8{ }^{\circ} \mathrm{C}\right)$. The first intermediate stock solutions containing concentration of $1.0 \mu \mathrm{g} / \mathrm{mL}$ of respective PGI were prepared from their corresponding primary stock solutions $(0.1 \mathrm{mg} / \mathrm{mL})$. First intermediate stock solutions $(1.0 \mu \mathrm{g} / \mathrm{mL})$ of each PGI were further diluted to yield primary standard solutions with concentration

Table 1 Summary of optimized liquid chromatographic and mass spectrometric method conditions

\begin{tabular}{|c|c|c|c|}
\hline Parameter & \multicolumn{3}{|l|}{ Condition } \\
\hline \multicolumn{4}{|l|}{ Liquid chromatography conditions } \\
\hline Mobile phase A & \multicolumn{3}{|c|}{ Acetonitrile:ammonium formate buffer ( $\mathrm{pH} 6$ ) (95:5). } \\
\hline Mobile phase B & \multicolumn{3}{|c|}{ Acetonitrile:ammonium formate buffer (pH 6) (50:50). } \\
\hline Auto-sampler temperature & \multicolumn{3}{|l|}{$25^{\circ} \mathrm{C}$} \\
\hline Column temperature & \multicolumn{3}{|l|}{$35^{\circ} \mathrm{C}$} \\
\hline Flow rate & \multicolumn{3}{|l|}{$0.8 \mathrm{~mL} / \mathrm{min}$} \\
\hline Injection volume & \multicolumn{3}{|l|}{$10 \mu \mathrm{L}$} \\
\hline Gradient program (time/mobile phase B) & \multicolumn{3}{|c|}{$0 / 5,3 / 10,6 / 40,8 / 70,10 / 70$} \\
\hline Run time & \multicolumn{3}{|l|}{$10 \min$} \\
\hline \multicolumn{4}{|l|}{ Mass spectrometry conditions } \\
\hline Source & \multicolumn{3}{|l|}{ ESI } \\
\hline Ionization mode & \multicolumn{3}{|l|}{ Positive } \\
\hline Capillary voltage & \multicolumn{3}{|l|}{$3.0 \mathrm{kV}$} \\
\hline Detection mode & \multicolumn{3}{|l|}{ MRM } \\
\hline MRM transitions $(\mathrm{m} / \mathrm{z})$ selected & PGI-1 & PGI-2 & PGI-3 \\
\hline For qualification & $163.1>126.3$ & $143.1>63.1$ & $80.5>63.1$ \\
\hline For quantification & $163.1>90.1$ & $143.1>107.1$ & $80.5>45.1$ \\
\hline Sample cone & \multicolumn{3}{|l|}{$15 \mathrm{~V}$} \\
\hline Probe temperature & \multicolumn{3}{|l|}{$150^{\circ} \mathrm{C}$} \\
\hline Heating block temperature & \multicolumn{3}{|l|}{$280^{\circ} \mathrm{C}$} \\
\hline Desolvation (DL) temperature & \multicolumn{3}{|l|}{$300{ }^{\circ} \mathrm{C}$} \\
\hline Nebulization and drying gas & \multicolumn{3}{|l|}{ Nitrogen } \\
\hline Nebulization gas flow & \multicolumn{3}{|l|}{$1.0 \mathrm{~mL} / \mathrm{min}$} \\
\hline Drying gas flow & \multicolumn{3}{|l|}{$900 \mathrm{~L} / \mathrm{h}$} \\
\hline CID gas & \multicolumn{3}{|l|}{ Argon } \\
\hline
\end{tabular}


of $100 \mathrm{ng} / \mathrm{mL}$ (50 ppm with respect to sample concentration of $2 \mathrm{mg} / \mathrm{ml}$ ). Calibration curve for standard solutions for each PGI were prepared by drawing appropriate aliquots of primary standard solution and diluting with acetonitrile. The linearity of the method was determined by six different standard solutions of each PGI. Linearity was achieved in the range of 16 to $200 \mathrm{ng} / \mathrm{mL}$ (8-100 ppm) for PGI-1; 22 to $200 \mathrm{ng} / \mathrm{mL}$ (11-100 ppm) for PGI-2 and 25 to $200 \mathrm{ng} / \mathrm{mL}(12.5-100 \mathrm{ppm})$ for PGI-3.

System suitability for the developed method was established by injecting six different replicates of primary standard solutions $(100 \mathrm{ng} / \mathrm{mL})$ of each of the PGIs and determining the relative standard deviation [RSD (\%)] of the obtained responses. For determining limit of detection (LOD) and limit of quantification (LOQ) values of the PGIs in the developed method, a series of standard solutions for each PGI were prepared in the concentration range of $2-30 \mathrm{ng} / \mathrm{mL}(\approx$ 1-15 ppm with respect $2 \mathrm{mg} / \mathrm{mL}$ API concentration) from their respective primary standard solutions (100 $\mathrm{ng} / \mathrm{mL}$ ).

Precision of the developed method was determined by performing repeatability (intra-day precision) and intermediate precision studies using the actual API samples. In the repeatability studies, six replicate samples containing $2 \mathrm{mg} / \mathrm{mL}$ of $\mathrm{APZ}$ were injected. Intermediate precision studies were performed by different analysts on different days using the same concentration of the API samples.

Accuracy studies of the method were performed using un-spiked and spiked samples of APIs. Triplicate samples of APZ at a $2 \mathrm{mg} / \mathrm{mL}$ concentration were prepared separately using acetonitrile as the diluent. Spiked samples were prepared by adding known volume of standard solutions of the PGIs at three different levels (LOQ, $100 \%$ and $150 \%)$ to API samples $(2 \mathrm{mg} / \mathrm{mL})$. Spiked samples were also prepared in triplicates.

For determining the robustness of the developed method, primary standard PGIs solutions of $100 \mathrm{ng} / \mathrm{mL}$ concentrations were used. The spiked samples of APZ of concentration: $2 \mathrm{mg} / \mathrm{mL}$ with three PGIs at $100 \%$ concentration levels were used in these robustness investigations. These studies were performed in triplicates.

\section{Method validation}

The developed method for the trace level quantification of PGI-1, PGI-2, and PGI-3 in APZ were systematically validated as per the analytical method validation guidance from regulatory agencies (Djordjevic Filijovic et al., 2014), International Conference on Harmonisation of Technical Requirements for Registration of Pharmaceuticals for Human Use, n.d.]. The method was validated for selectivity, sensitivity, linearity, precision, accuracy, and robustness. Stability studies of all the PGIs were also performed to assess their stability during short-term sample processing and long-term storage.

\section{Specificity}

Specificity was determined by injecting the diluent blank, process impurities, and solvents. The interference should be less than the limit of detection (LOD).

\section{Sensitivity}

Limit of detection (LOD) and limit of quantification (LOQ) of each PGIs were determined by injecting different standard solutions of PGI-1, PGI-2, and PGI-3 as described in the "Preparation of stock solutions and sample solutions" section, to obtain a signal-to-noise (S/ N) ratio greater than or equal to $3: 1$ and 10:1, respectively.

\section{Linearity}

Calibration curves were constructed for each PGI by plotting the response against the respective concentration of PGIs. Unweighted regression analysis was performed to fit the calibration curves of each PGI and to determine the regression equations. Statistical parameters like slope, intercept, and regression coefficient $\left(R^{2}\right)$ were determined to analyze the goodness of fit and validity of regression.

\section{Precision}

In repeatability as well as in the intermediate precision studies, RSD (\%) values of the responses of each PGI (at 100\% level) were obtained by injecting six replicate samples containing $2 \mathrm{mg} / \mathrm{mL}$ of API. RSD (\%) values of PGI responses from the six replicates should be less than $10 \%$ to confirm the repeatability of the method.

To establish intermediate precision of the developed method, RSD (\%) values of each PGI were determined by varying different analysts on different days. RSD (\%) values should be less than $20 \%$ to indicate that the developed method was precise.

\section{Accuracy}

Accuracy of the method was determined in terms of percentage recovery and RSD (\%) values for each of the PGI by comparing the responses obtained from un-spiked and spiked samples at three different levels ranging from LOQ, $100 \%$ and $150 \%$ of the specification limit of 50 ppm. Percentage recovery values should be within $100 \pm$ $20 \%$ while the RSD (\%) values should be less than $10 \%$ to establish that the method was accurate. 


\section{Robustness}

Robustness of the developed method was determined by deliberately changing mobile phase flow rate $( \pm 20 \%$ to the set value of $0.8 \mathrm{~mL} / \mathrm{min})$ and cone voltage $( \pm 20 \%$ to the set value of $15 \mathrm{~V}$ ). System suitability and mean percentage recovery of the spiked samples were determined by changing the method parameters as described above. RSD (\%) values obtained from system suitability should be $\leq 10 \%$ and mean percentage recovery should be within $100 \pm 20 \%$ for each PGI.

\section{Solution Stability}

Stability studies were performed using secondary intermediate stock solution $(100 \mathrm{ng} / \mathrm{mL})$ of each PGI and spiked samples of APZ $(2 \mathrm{mg} / \mathrm{mL})$ with PGIs at $100 \%$ concentration levels up to $48 \mathrm{~h}$ at ambient laboratory temperature $\left(25 \pm 5{ }^{\circ} \mathrm{C}\right)$ and refrigerated condition $\left(2-8{ }^{\circ} \mathrm{C}\right)$. The percent recoveries of primary standard solutions of each PGI and spiked samples subjected to stability studies were calculated by comparing against the freshly prepared primary standard solutions $(100 \mathrm{ng} / \mathrm{mL})$ of each PGI.

\section{Results and discussions}

Optimization of chromatographic and mass spectrometric method conditions

Considering the small molecular size and polar nature of the analytes under investigation, hydrophilic interaction liquid chromatography (HILIC) was applied. In this study, different stationary phases such as Inertsil HILIC, Luna HILIC, Zic HILIC, and ACE HILIC-N columns with varied polarity were evaluated with LC-MS compatible aqueous mobile phases such as ammonium formate and ammonium acetate buffers (in variable ratios) to optimize the separation of PGIs from the API and also to obtain better sensitivity in their MS response. Both isocratic and gradient elution modes were evaluated for the optimal resolution between analytes and API. Better peak shapes and resolution of PGIs and APZ were obtained with ACE HILIC-N Column $(100 \mathrm{~mm} \times 4.6 \mathrm{~mm}$ $\times 5 \mu \mathrm{m})$ in gradient elution mode using mobile phase $\mathrm{A}$ consisting of acetonitrile:ammonium formate buffer (95: $5 \mathrm{v} / \mathrm{v}$ ) and mobile phase B comprising of acetonitrile:ammonium formate buffer $(50: 50 \mathrm{v} / \mathrm{v})$.

Mass spectrometer (MS) conditions were optimized in positive ionization mode. For the quantification of the analytes, multiple reaction monitoring (MRM) mode was employed. Various MS parameters such as heating block temperature, desolvation line (DL) temperature, and drying gas flow were studied to achieve optimum response for all the PGIs in MRM mode. Fragmentation patterns for PGI-1, PGI-2, and PGI-3 are presented in Fig. 2. Optimized chromatographic and mass spectrometric method conditions for qualification and quantification of PGI-1, PGI-2, and PGI-3 are presented in Table 1.

\section{Method validation Specificity}

The total ion current (TIC) chromatograms showing the separation between PGIs and APZ are presented in Fig. 3. Typical MS chromatograms of blank, standard PGI (at $50 \mathrm{ppm}$ ), and spiked sample of APZ with PGIs at their corresponding $\mathrm{m} / \mathrm{z}$ transition in MRM mode are presented in Fig. 4. As shown in Fig. 4a, no interfering peaks were seen at retention times of PGIs and APZ in the obtained MS chromatogram. The areas of diluent blank samples at the $\mathrm{m} / \mathrm{z}$ transitions of each PGI were well within the acceptance limits when compared with the areas of PGIs at their LOQ levels.

\section{Sensitivity}

LOD concentrations for PGI-1, PGI-2, and PGI-3 were found to be $2.5 \mathrm{ppm}, 3.5 \mathrm{ppm}$, and $4.0 \mathrm{ppm}$, respectively, with respect to $2 \mathrm{mg} / \mathrm{mL}$ sample concentration. LOQ concentration for PGI-1, PGI-2, and PGI-3 was found to be $8 \mathrm{ppm}, 11 \mathrm{ppm}$, and $12.5 \mathrm{ppm}$, respectively, with respect to $2 \mathrm{mg} / \mathrm{mL}$ sample concentration. RSD (\%) values of six replicate injections of PGI-1, PGI-2, and PGI-3 at LOQ level were found to be $4.13 \%, 4.21 \%$, and $3.29 \%$, respectively (Table 2 ). Stack overlay of extraction ion chromatogram showing LOD and LOQ solutions (PGI-1, PGI-2, and PGI-3) is shown in Fig. 5.

\section{Linearity}

The calibration curves for PGI-1 (range 8-100 ppm), PGI-2 (range 11-100 ppm), and PGI-3 (range 12.5-100 ppm) were constructed with peak area on vertical axis and concentration of analyte on horizontal axis. From linear regression analysis, slope, intercept, and $R^{2}$ values were determined and results are summarized in Table 2. In the linear regression analysis for each of the PGIs, the $R^{2}$ values are above 0.99 and acceptable RSD (\%) over the concentration ranges confirm that the developed method for the three PGIs is linear. Overlay of regression study linearity plot of PGI-1, PGI-2, and PGI-3 are depicted in Fig. 6.

\section{Precision}

The results obtained from precision studies are given in Table 2. Cumulative RSD (\%) values for the results obtained from analyst variation (analyst 1 and analyst 2) were within the acceptance criteria of $\leq 10 \%$. RSD (\%) for each PGI content from six preparations in the precision and intermediate precision experiments were within the acceptance criteria of $\leq 10.0 \%$ indicating that the developed method is precise for the trace level quantification of PGI-1, PGI-2, and PGI-3. 


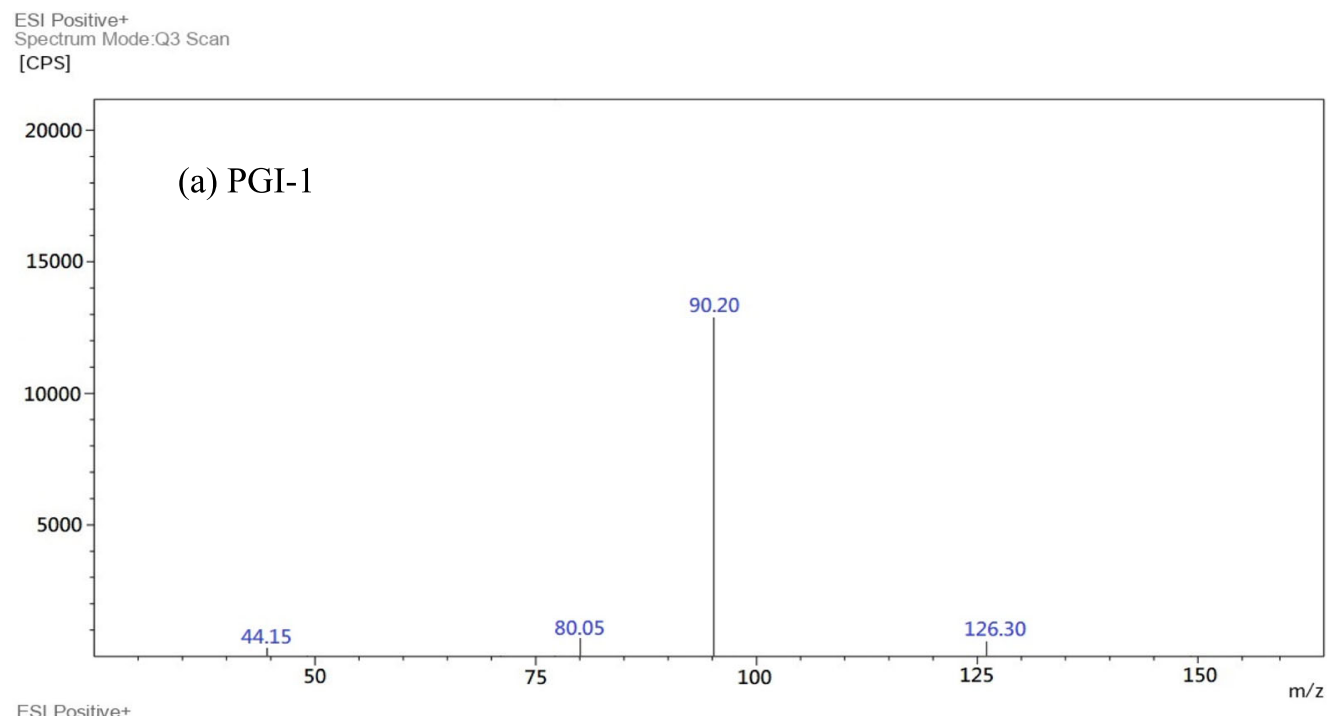

ESI Positive+

pectrum Mode:Q3 Scan

[CPS]

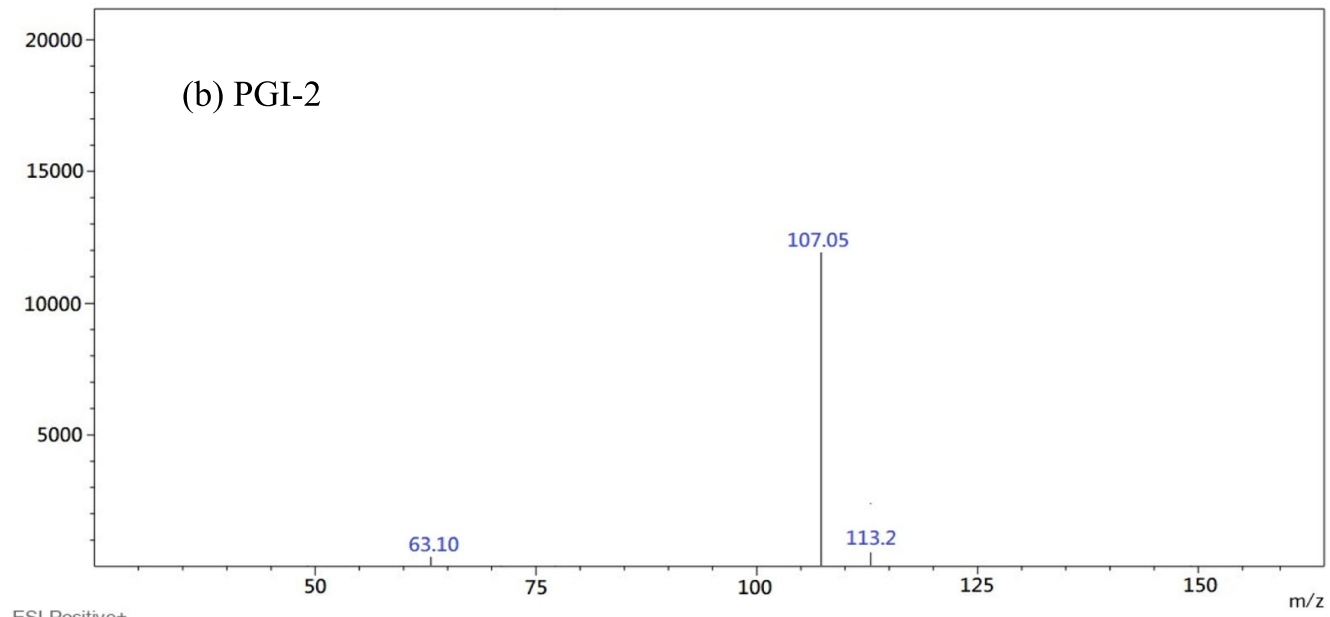

ESI Positive+

作

[CPS]

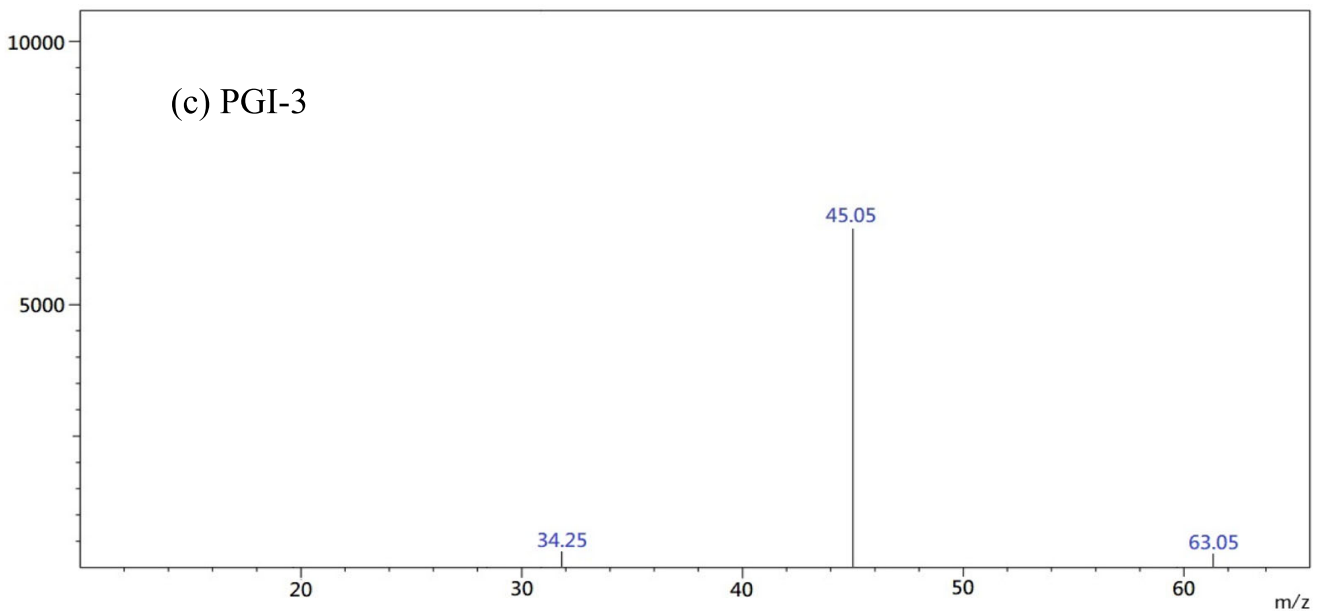

Fig. 2 Fragmentation pattern of a PGI-1, b PGI-2, and c PGl-3 

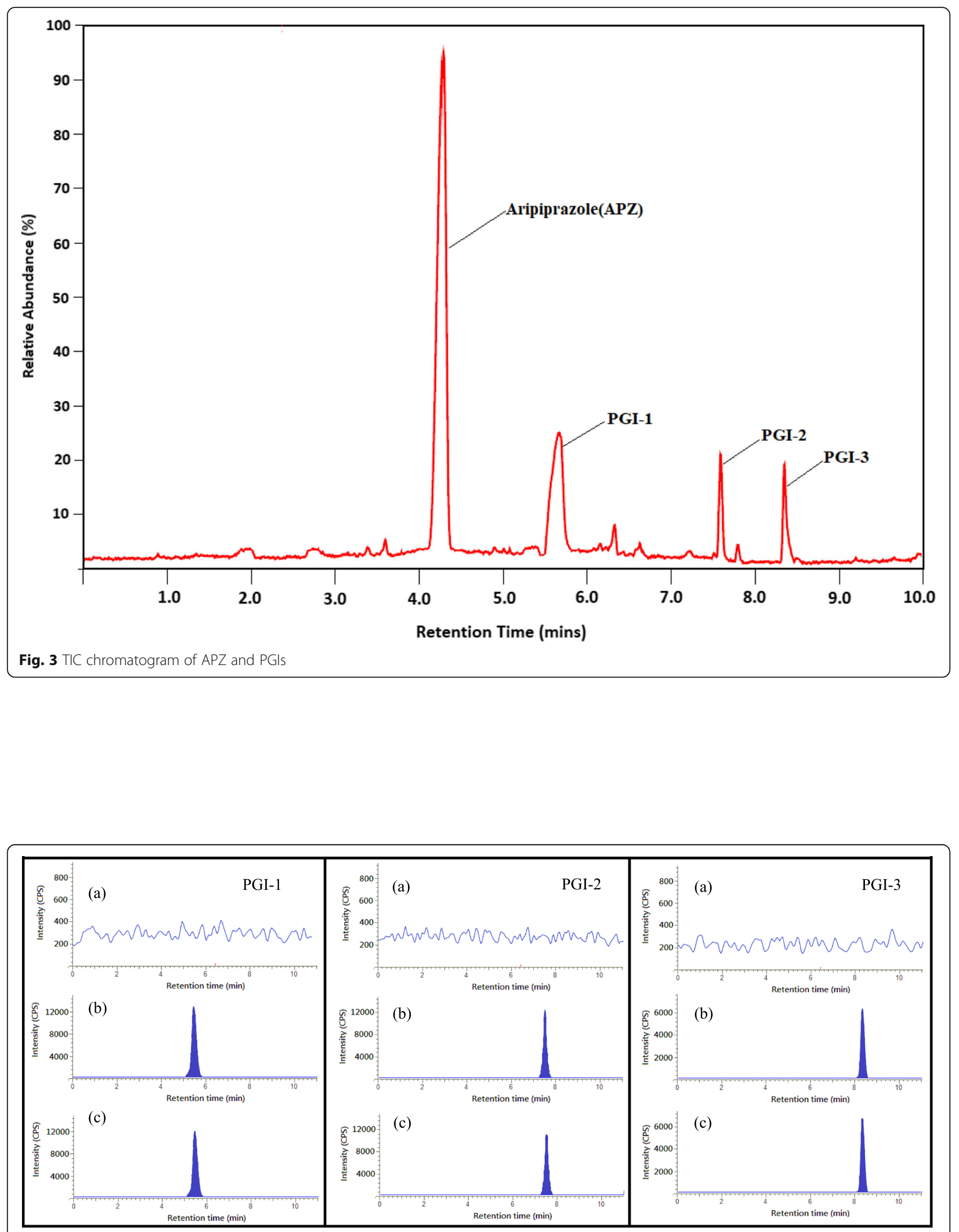

Fig. 4 MRM chromatograms of PGI-1, PGI-2, and PGI-3. a Blank. b Un-spiked PGI standard at 50 ppm. c PGl standard at 50 ppm spiked with APZ 
Table 2 Summary of method validation results

\begin{tabular}{|c|c|c|c|c|}
\hline \multirow[t]{2}{*}{ Test parameter } & \multirow[t]{2}{*}{ Typical acceptance criteria } & \multicolumn{3}{|l|}{ Result } \\
\hline & & PGI-1 & PGI-2 & PGI-3 \\
\hline System suitability & RSD (\%) for peak area response $(n=6)$ & $0.97 \%$ & $1.62 \%$ & $1.94 \%$ \\
\hline Specificity & Interference from blank & No interference & No interference & No interference \\
\hline \multirow[t]{2}{*}{ Sensitivity } & Concentration & $\begin{array}{l}\text { LOD-2.5 ppm } \\
\text { LOQ-8.0 ppm }\end{array}$ & $\begin{array}{l}\text { LOD-3.5 ppm } \\
\text { LOQ-11.0 ppm }\end{array}$ & $\begin{array}{l}\text { LOD-4.0 ppm } \\
\text { LOQ-12.5 ppm }\end{array}$ \\
\hline & $\begin{array}{l}\text { RSD for six replicate injections of LOQ } \\
\text { solution should be } \leq 15.0 \%\end{array}$ & $4.13 \%$ & $4.21 \%$ & $3.29 \%$ \\
\hline \multirow[t]{3}{*}{ Linearity } & Range & 2.5-100 ppm & 3.5-100 ppm & 4.0-100 ppm \\
\hline & Calibration equation & $y=130.97 x+178.5$ & $y=123.16 x-41.816$ & $y=69.578 x-36.595$ \\
\hline & $R^{2}$ & 0.9992 & 0.9969 & 0.9997 \\
\hline Accuracy & $\begin{array}{l}\text { Average recovery }(n=3) \text { from the spiked } \\
\text { samples performed at } 3 \text { levels-LOQ-150\%; } \\
\text { RSD should be } \leq 10.0 \%\end{array}$ & $\begin{array}{l}\text { LOQ-96.9\%; } 1.28 \% \\
100 \%-100.1 \% ; 1.88 \% \\
150 \%-100.5 \% ; 0.97 \%\end{array}$ & $\begin{array}{l}\text { LOQ-98.9\%; } 1.98 \% \\
100 \%-99.8 \% ; 2.08 \% \\
150 \%-99.0 \% ; 1.11 \%\end{array}$ & $\begin{array}{l}\text { LOQ-99.3\%; } 3.57 \% \\
\text { 100\%-98.8\%; } 1.36 \% \\
150 \%-97.7 \% ; 1.35 \%\end{array}$ \\
\hline $\begin{array}{l}\text { Precision } \\
\text { (analyst 1) }\end{array}$ & $\begin{array}{l}\text { RSD (\%) for six preparations at } 100 \% \text { level } \\
\text { should be } \leq 10.0 \%\end{array}$ & $2.37 \%$ & $3.15 \%$ & $2.94 \%$ \\
\hline $\begin{array}{l}\text { Intermediate precision } \\
\text { (analyst 2) }\end{array}$ & $\begin{array}{l}\text { RSD }(\%) \text { for six preparations at } 100 \% \text { level } \\
\text { should be } \leq 10.0 \%\end{array}$ & $2.96 \%$ & $3.42 \%$ & $3.83 \%$ \\
\hline Solution stability & $\begin{array}{l}\text { Standard and } 100 \% \text { spiked solution stored at } \\
\text { ambient laboratory conditions }\left(25 \pm 5^{\circ} \mathrm{C}\right) \text { and } \\
\text { refrigerated conditions } \\
\left(2-8{ }^{\circ} \mathrm{C}\right) \text { were studied for } 48 \mathrm{~h}\end{array}$ & Stable for $48 \mathrm{~h}$ & Stable for $48 \mathrm{~h}$ & Stable for $48 \mathrm{~h}$ \\
\hline \multirow[t]{4}{*}{ Robustness } & $\begin{array}{l}\text { RSD }(\%) \text { for peak area response }(n=6) \text { with } \\
0.7 \mathrm{~mL} / \mathrm{min} \text { flow rate } \\
\% \text { Recovery }(n=3) \text { for } 100 \% \text { spiked solution }\end{array}$ & $\begin{array}{l}1.28 \% \\
100.1 \%\end{array}$ & $\begin{array}{l}1.94 \% \\
98.7 \%\end{array}$ & $\begin{array}{l}1.82 \% \\
96.8\end{array}$ \\
\hline & $\begin{array}{l}\text { RSD }(\%) \text { for peak area response }(n=6) \text { with } \\
1.0 \mathrm{~mL} / \mathrm{min} \text { flow rate } \\
\% \text { Recovery }(n=3) \text { for } 100 \% \text { spiked solution }\end{array}$ & $\begin{array}{l}4.1 \% \\
96.5 \%\end{array}$ & $\begin{array}{l}3.4 \% \\
96.8 \%\end{array}$ & $\begin{array}{l}3.5 \% \\
95.2 \%\end{array}$ \\
\hline & $\begin{array}{l}\text { RSD }(\%) \text { for peak area response }(n=6) \text { with } \\
12 \mathrm{~V} \text { cone voltage } \\
\% \text { Recovery }(n=3) \text { for } 100 \% \text { spiked solution }\end{array}$ & $\begin{array}{l}1.34 \% \\
99.6 \%\end{array}$ & $\begin{array}{l}1.9 \% \\
97.7 \%\end{array}$ & $\begin{array}{l}2.2 \% \\
97.4 \%\end{array}$ \\
\hline & $\begin{array}{l}\text { RSD }(\%) \text { for peak area response }(n=6) \text { with } \\
18 \vee \text { cone voltage } \\
\% \text { Recovery }(n=3) \text { for } 100 \% \text { spiked solution }\end{array}$ & $\begin{array}{l}3.1 \% \\
95.3 \%\end{array}$ & $\begin{array}{l}4.3 \% \\
94.7 \%\end{array}$ & $\begin{array}{l}4.9 \% \\
93.8 \%\end{array}$ \\
\hline
\end{tabular}

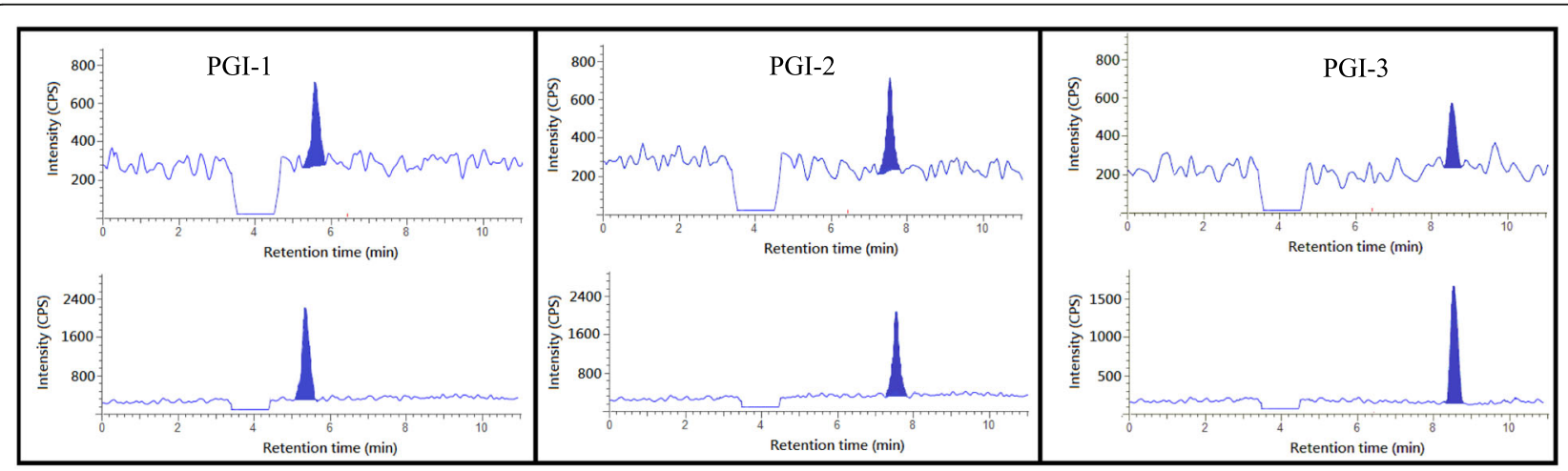

Fig. 5 MRM chromatograms of PGI-1, PGI-2, and PGI-3 for their evaluation of LOD and LOQ values 


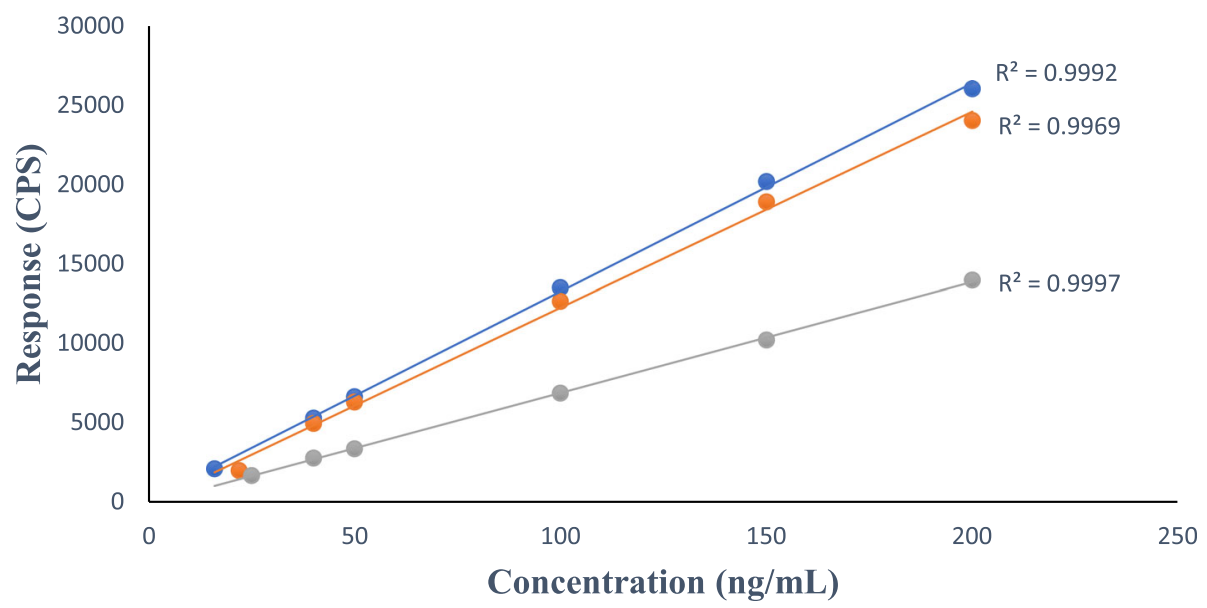

Fig. 6 Linearity plot of PGI-1, PGI-2, and PGI-3

\section{Accuracy}

The results obtained from accuracy studies are summarized in Table 2. Percentage recovery values of each of the PGIs, at all the three levels, were found to be more than 95\% with RSD (\%) less than 4\%. These results indicate that the developed method was accurate as the percentage recovery and \%RSD values were found to be well within the acceptable limits of $100 \pm 20 \%$ and $\leq$ $10 \%$, respectively.

\section{Robustness}

Robustness of the method was evaluated for mobile phase flow rate $(0.7$ and $1.0 \mathrm{~mL} / \mathrm{min})$ and cone voltage $(12 \mathrm{~V}$ and $18 \mathrm{~V})$ and the results obtained are presented in Table 2. RSD (\%) from six replicate injections of system suitability solution of all the PGIs for the change in mobile phase flow rate and cone voltage were less than $5.0 \%$. Percentage recovery values of triplicate spiked sample injections of all the PGIs for the change in mobile phase flow rate and cone voltage were more than 93\%. The results obtained for robustness studies were found to be well within the acceptance criteria of not more than $10 \%$ (RSD) and within $100 \pm 20 \%$ for percentage recovery.

\section{Solution stability}

Short-term solution stability for primary standard solution $(100 \mathrm{ng} / \mathrm{mL})$ of each PGI and spiked samples of APZ (2 mg/mL) with PGIs at $100 \%$ concentration levels were studied up to $48 \mathrm{~h}$ at ambient laboratory temperature $\left(25 \pm 5{ }^{\circ} \mathrm{C}\right)$ and refrigerated condition $\left(2-8{ }^{\circ} \mathrm{C}\right)$. The percent recoveries of each PGI in primary standard solution and spiked samples were calculated by comparing against the freshly prepared primary standard solutions of respective PGI standard. No significant difference $(<10 \%$ to the initial result) was observed in the stability of the samples when stored at ambient laboratory temperature $\left(25 \pm 5{ }^{\circ} \mathrm{C}\right)$ and refrigerated condition $\left(2-8{ }^{\circ} \mathrm{C}\right)$ for a period of $48 \mathrm{~h}$.

\section{Application}

The methodology developed was applied to the aripiprazole drug product available in the market. The sample solutions were prepared by ensuring the final concentration should remain $2.0 \mathrm{mg} / \mathrm{mL}$ in line with aripiprazole drug. The results show the absence of any of the PGI impurities in the said drug formulations. Hence, known amounts of PGI impurities were added to the drug solutions and recovery studies were made. The results are

Table 3 Summary of drug product application results

\begin{tabular}{lllll}
\hline Test parameter & Sample name & Result & \\
\cline { 2 - 4 } & & PGI-1 & PGI-2 & PGI-3 \\
\hline Product samples analysis & Arpizol 5 Tablet & BDL & BDL & BDL \\
& Asprito 5 Tablet & BDL & BDL & BDL \\
Accuracy & Arip MT 5 Tablet & BDL & $96.4 \%$ & $97.1 \%$ \\
& Typical acceptance criteria & $98.2 \%$ & & \\
& Average recovery $(n=3)$ from the spiked drug & & \\
& product samples performed at 100\% level & & \\
\hline
\end{tabular}


presented in Table 3 . The \% of recovery falls between 96.4 and $98.2 \%$. Hence, the method developed can be successfully applied to assay the level of 3 PGI impurities in drug formulations.

\section{Conclusions}

LC-MS/MS method was developed and validated for the trace level quantification of 2,3-dichloroaniline (PGI-1), bis(2-chloroethyl) amine (PGI-2), and 2-chloroethylamine (PGI-3) in aripiprazole which are potential genotoxic impurities. Resolution was achieved by employing the HILIC chromatographic method. Validation results substantiate that the developed method was selective, sensitive, accurate, and precise for the quantification of the PGIs in APZ. Standard solutions of all the PGIs were found to be stable for $48 \mathrm{~h}$ at ambient and refrigerated conditions. Hence, the developed method can be used by pharmaceutical industries for trace quantification of the PGIs in aripiprazole API and formulations.

\section{Abbreviations}

APZ: Aripiprazole; HILIC: Hydrophilic interaction liquid chromatography; MDD: Maximum daily dose; MRM: Multiple reaction monitoring: PGI: Potential genotoxic impurity; RSD: Relative standard deviation; TIC : Total ion current; BDL: Below detection level; API: Active pharmaceutical ingredient

\section{Acknowledgements}

The authors are thankful to the management of $\mathrm{K} L$ University, Guntur, Andhra Pradesh, for providing necessary support to the current research work.

\section{Authors' contributions}

Sumanth Mullangi and Kunta Ravindhranath contributed in designing and planning this research. Sumanth Mullangi developed and validated the method as per investigation plan. Sumanth Mullangi prepared the draft manuscript and Ravi Kiran contributed in statistical analysis and writing of the manuscript. Kunta Ravindhranath corrected and aligned the manuscript as per the journal submission guidelines. All authors contributed in reading and approving the final manuscript.

\section{Funding}

Not applicable

\section{Availability of data and materials}

Not applicable

\section{Declarations}

\section{Competing interests}

The authors declare that they have no competing interests.

\section{Author details}

'Department of Chemistry, Koneru Lakshmaiah Education Foundation, Green Fields, Vaddeswaram-522 502, Guntur Dt., A.P, India. ²Department of Chemistry, BITS-Pilani Hyderabad Campus, Jawaharnagar, Hyderabad, Medchal (Dist), Telangana 500078, India.

Received: 4 February 2021 Accepted: 9 April 2021

Published online: 21 April 2021

\section{References}

Ambavaram VB, Nandigam V, Vemula M, Kalluru GR, Gajulapalle M. Liquid chromatography-tandem mass spectrometry method for simultaneous quantification of urapidil and aripiprazole in human plasma and its application to human pharmacokinetic study. Biomed. Chromatogr. 2013; 27(7):916-23. https://doi.org/10.1002/bmc.2882.

Caloro M, Lionetto L, Cuomo I, Simonetti A, Pucci D, De Persis S, et al. An improved simple LC-MS/MS method for the measurement of serum aripiprazole and its major metabolite. J. Pharm. Biomed. Anal. 2012;62:135-9. https://doi.org/10.1016/j.jpba.2012.01.003.

Djordjevic Filijovic N, Pavlovic A, Nikolic K, Agbaba D. Validation of an HPLC method for determination of aripiprazole and its impurities in pharmaceuticals. Acta. Chromatogr. 2014;26(1):13-28. https://doi.org/10.1 556/AChrom.26.2014.1.15.

International Council for Harmonization, .n.d.-a, M7 guideline: assessment and control of DNA reactive (Mutagenic) impurities in pharmaceuticals to limit potential carcinogenic risk. https://database.ich.org/sites/default/files/M7_R1_ Guideline.pdf

International Council for Harmonization, n.d.-b, Q3A (R2) guideline: impurities in new drug substances. https://database.ich.org/sites/default/files/Q3A_R2 Guideline.pdf

International Conference on Harmonisation of Technical Requirements for Registration of Pharmaceuticals for Human Use, n.d., ICH Harmonised Tripartite Guideline, Validation of analytical procedures: Text and Methodology Q2(R1). https://database.ich.org/sites/default/files/Q2\%28R1\%2 9\%20Guideline.pdf.

Keck PE, Marcus R, Tourkodimitris S, Ali M, Liebeskind A, Saha A. A placebocontrolled, double-blind study of the efficacy and safety of aripiprazole in patients with acute bipolar mania. Am. J. Psychiatry. 2003;160(9):1651-8. https://doi.org/10.1176/appi.ajp.160.9.1651.

Keck PE, Orsulak PJ, Cutler AJ, Sanchez R, Torbeyns A, Marcus RN. Aripiprazole monotherapy in the treatment of acute bipolar I mania: a randomized double-blind, placebo- and lithium-controlled study. J. Affect. Disord. 2009; 112(1-3):36-49. https://doi.org/10.1016/j.jad.2008.05.014.

Kubo M, Mizooku Y, Hirao Y, Osumi T. Development and validation of an LC-MS/ MS method for the quantitative determination of aripiprazole and its main metabolite, OPC-14857, in human plasma. J. Chromatogr. B. 2005;822(1-2): 294-9. https://doi.org/10.1016/j.jchromb.2005.06.023.

Kwon JS, Jang JH, Kang DH. Long-term efficacy and safety of aripiprazole in patients with schizophrenia, schizophreniform disorder, or schizoaffective disorder: 26-week prospective study. Psyc. Clini. Neurosci. 2009;63(1):73-81. https://doi.org/10.1111/j.1440-1819.2008.01907.x.

Liang F, Terry AV, Bartlett MG. Determination of aripiprazole in rat plasma and brain using ultra-performance liquid chromatography/electrospray ionization tandem mass spectrometry. Biomed. Chromatogr. 2012;26(11):1325-32. https://doi.org/10.1002/bmc.2698.

Lin SN, Lamm L, Newton TF, Reid MS, Moody DE, Foltz RL. A liquid chromatography-electrospray ionization-tandem mass spectrometry method for quantitation of aripiprazole in human plasma. J. Anal. Toxicol. 2009;33(5): 237-42. https://doi.org/10.1093/jat/33.5.237.

McGovern Y, Jacobson-Kram T. Regulation of genotoxic and carcinogenic impurities in drug substances and products. Trend. Anal. Chem. 2006;25(8): 790-5. https://doi.org/10.1016/j.trac.2006.06.004.

Muller L, Mauthe RJ, Riley CM, Andino MM, Antonis DD, Beels C, et al. A rationale for determining, testing, and controlling specific impurities in pharmaceuticals that possess potential for genotoxicity. Reg. Toxicol. Pharmacol. 2006;44(3):198-211. https://doi.org/10.1016/j.yrtph.2005.12.001.

Patel DP, Sharma P, Sanyal M, Shrivastav PS. SPE-UPLC-MS/MS method for sensitive and rapid determination of aripiprazole in human plasma to support a bioequivalence study. J. Chromatogr. B. 2013;925:20-5. https://doi. org/10.1016/j.jchromb.2013.02.022.

Robinson DI. Control of genotoxic impurities in active pharmaceutical ingredients: A review and perspective. Org. Process Res. Dev. 2010;14(4):94659. https://doi.org/10.1021/op900341a.

Sachs G, Sanchez R, Marcus R, Stock E, McQuade R, Carson W. Aripiprazole in the treatment of acute manic or mixed episodes in patients with bipolar I disorder: a 3-week placebo-controlled study. J. Psychopharmacol. 2006;20(4): 536-46. https://doi.org/10.1177/0269881106059693.

Sharif ZA, Lieberman RA, Schatzberg AF, Nemeroff CB. Textbook of Psychopharmacology. Washington, DC: The American Psychiatric Publishing American Psychiatric Pub. Inc; 2009. p. 613-25.

Snodin DJ. Genotoxic impurities: From structural alerts to qualification. Org Process Res. Dev. 2010;14(4):960-76. https://doi.org/10.1021/op100118e.

Song M, Xu X, Hang T, Wen A, Yang L. Development of an LC-MS/MS method for the simultaneous quantification of aripiprazole and dehydro-aripiprazole 
in human plasma. Anal. Biochem. 2009;385(2):270-7. https://doi.org/10.1016/ j.ab.2008.11.027.

United states food and drug administration, n.d., S2 (R1) guideline: genotoxicity testing and data interpretation for pharmaceuticals intended for human use. https://www.fda.gov/regulatory- information/search-fda-guidancedocuments/s2r1-genotoxicity-testing-and-data-interpretation- pharmaceutica Is-intended-human-use

Vieta E, Tjoen C, McQuade RD, Carson WH, Marcus RN, Sanchez R. Efficacy of adjunctive aripiprazole to either valproate or lithium in bipolar mania patients partially nonresponsive to valproate/ lithium monotherapy: a placebo-controlled study. Am. J. Psychiatry. 2008;165(10):1316-25. https://doi. org/10.1176/appi.ajp.2008.07101560.

\section{Publisher's Note}

Springer Nature remains neutral with regard to jurisdictional claims in published maps and institutional affiliations.

\section{Submit your manuscript to a SpringerOpen ${ }^{\circ}$ journal and benefit from:}

- Convenient online submission

- Rigorous peer review

- Open access: articles freely available online

- High visibility within the field

- Retaining the copyright to your article

Submit your next manuscript at $\boldsymbol{\nabla}$ springeropen.com 